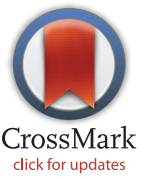

click for updates

RESEARCH ARTICLE

\title{
Asymmetric Mating Interference between Two Related Mosquito Species: Aedes (Stegomyia) albopictus and Aedes (Stegomyia) cretinus
}

\author{
Athanassios Giatropoulos ${ }^{1,2}$ *, Dimitrios P. Papachristos ${ }^{3}$, George Koliopoulos ${ }^{1}$, \\ Antonios Michaelakis ${ }^{3}$, Nickolaos Emmanouel ${ }^{2}$
}

1 Laboratory of Biological Control of Pesticides, Department of Pesticides Control \& Phytopharmacy, Benaki Phytopathological Institute, Kifissia, Athens, Greece, 2 Laboratory of Agricultural Zoology and Entomology, Agricultural University of Athens, Athens, Greece, 3 Laboratory of Agricultural Entomology, Department of Entomology and Agricultural Zoology, Benaki Phytopathological Institute, Kifissia, Athens, Greece

* a.giatropoulos@bpi.gr

\section{G open Access}

Citation: Giatropoulos A, Papachristos DP Koliopoulos G, Michaelakis A, Emmanouel N (2015) Asymmetric Mating Interference between Two Related Mosquito Species: Aedes (Stegomyia) albopictus and Aedes (Stegomyia) cretinus. PLoS ONE 10(5): e0127762. doi:10.1371/journal. pone. 0127762

Academic Editor: John Vontas, University of Crete, GREECE

Received: January 16, 2015

Accepted: April 19, 2015

Published: May 22, 2015

Copyright: ๑ 2015 Giatropoulos et al. This is an open access article distributed under the terms of the Creative Commons Attribution License, which permits unrestricted use, distribution, and reproduction in any medium, provided the original author and source are credited.

Data Availability Statement: All relevant data are within the paper.

Funding: This study was supported by the Development \& demonstration of management plans against -the climate change enhanced- invasive mosquitoes in South Europe (LIFE CONOPS LIFE12 ENV/GR/000466), funded by the European Commission in the framework of the programme LIFE

+ Environment Policy and Governance (www.conops. gr; http://ec.europa.eu/environmentllife/index.htm) (to AM). The funders had no role in study design, data

\section{Abstract}

Aedes (Stegomyia) albopictus (Skuse) and Aedes (Stegomyia) cretinus Edwards are closely related mosquito species with common morphological features and bio-ecological similarities. Recent mosquito surveillance in Athens, Greece, showed that they are sympatric mosquito species, with Ae. Albopictus developing quite higher population densities than Ae. Cretinus. The potential of mating interference between these species was investigated by reciprocal and homologous mating experiments in cages under laboratory conditions. In non-choice interspecific crosses (groups of males and females) females of both species produced sterile eggs. Insemination rate was $58 \%$ for Ae. Cretinus females and only $1 \%$ for Ae. Albopictus females. Aedes albopictus males were sexually aggressive and inseminated Ae. Cretinus females (31\%) in choice experiments, where males of one species had access to mate with females of both species. Whereas, interspecific mating of Ae. Albopictus females with Ae. Cretinus males in the co-occurrence of Ae. Cretinus females was weaker (4\%). Aedes cretinus females from non-choice crossing with Ae. Albopictus or Ae. Cretinus males were paired individually with conspecific males. The percentage of fertile Ae. Cretinus females was $17.5 \%$ when had encaged before with Ae. Albopictus males, compared to $100 \%$ when Ae. Cretinus females were encaged with conspecific males only. Probable ecological consequences of asymmetric mating between these ecologically homologous species in nature are discussed.

\section{Introduction}

Competitive displacement principle describes the phenomenon of displacement or extinction of a species from another ecologically homologous species that shares the same ecological 
collection and analysis, decision to publish, or preparation of the manuscript.

Competing Interests: The authors have declared that no competing interests exist. niche [1]. This type of displacement affects the range of species distribution and is the most severe outcome of interspecific competition in insects and arachnids, where both exploitation and interference mechanisms are implicated [2]. It has primarily been occurred between closely related species in cases where exotic species displayed native species or previously established exotic species, often due to human interventions, in the contest of biotic invasions or species introduction for biological control [2-4].

"Mating interference" or "satyrization" or "reproductive competition", i.e. negative effects via interspecific mating depressing reproductive output, is one of the multiple mechanisms that may underlie the phenomenon of "competitive displacement" or "competitive reduction" in mosquitoes [4-7]. Asymmetric mating interference, whereby males of one species mate with a related species and produce inviable or less fit hybrid offspring or infertile eggs, has been proposed as a method for the biological control of pests and vectors [8] and as a mechanism that maintains parapatric distributions of related species in nature [5]. Mating interference may explain the parapatric distribution of certain tsetse flies in Africa [9], the dynamics of hybrid zones between tick species [10] and has been proposed as the cause for the parapatric distribution of the mosquitoes Aedes aegypti (L.) and Ae. bahamensis (Coquillett) on Grand Bahama Island [11].

Aedes (Stegomyia) albopictus (Skuse 1894), the so-called Asian tiger mosquito, is considered to be the most invasive mosquito species in the world possessing serious impact on biological diversity and human activities [12]. Among the invasive mosquito species detected in Europe, Ae. albopictus probably presents the major threat to public health [13]. It is a serious nuisance biting mosquito that is implicated in the transmission of a wide range of human pathogens, such as dengue and chikungunya virus and filarial nematods of the genus Dirofilaria [14]. Due to its quick and aggressive spread from its native range in East Asia and islands of the Western Pacific and Indian Ocean, Ae. albopictus has colonized every continent except Antarctica in the past 30-40 years [15]. Cross mating advantage of Ae. albopictus in reproductive competition with other native container breeding Aedes species has been considered among multiple hypotheses concerning the ecological processes operating during its invasions in several locations $[6,7,16,17]$.

After its first detection in 2003-2004 in Northwestern Greece [18], Ae. albopictus has been subsequently found in several areas of the country [19]. A recent field work using ovitraps in the greater urban area of Athens showed that Ae. albopictus was widespread in the studied area performing considerably high ovipositioning activity, and revealed the presence of the indigenous mosquito Aedes (Stegomyia) cretinus (Edwards 1921) in negligible and restricted, however, population densities [20]. Aedes albopictus predominated in the well urbanized areas while Ae. cretinus was active only in the less crowded and more vegetated area where both species, however, co-occurred and maybe were given the opportunity to meet and interbreed [20]. Aedes cretinus shares many morphological and behavioral traits with Ae. albopictus [21], and both species have been placed into the subgroup albopictus (group scutellaris) of the subgenus Stegomyia [22]. The classification of these two Aedes species was revised by Reinert et al [23], though not generally accepted $[24,25]$, so the subgenus of these two species under this new classification is currently uncertain. Aedes cretinus has a limited distribution across the world (Greece, Cyprus, Georgia and Turkey) and little appears to be known about its biology, while its capacity to transmit diseases has not been investigated [26]. It has been described as an aggressive day time biting tree-hole mosquito from wooded areas in Greece [27] and primarily wooded areas, open fields and road edges in Turkey [28,29].

Once a female mosquito has undergone a consummated union, usually becomes refractory to subsequent mating, at least until after completing a gonotrofic cycle. At a certain time after mating, the initial refractoriness of the female is reinforced by a pheromone, named matronae, 
which is contained in male accessory gland (MAG) secretions, transferred to her in semen fluid during copulation $[26,30,31]$. Induced female monogamy by MAG secretions that act either as a short-term mating plug physical barrier [32,33] or as a long-term chemical barrier to further insemination, has been shown to occur in Aedes mosquitoes [31,34-37] and particularly in Ae. albopictus $[34,38,39]$. Thus, mating interference between different mosquito species could sterilize a female that cannot produce viable offspring [40,41]. The tendency for Ae. albopictus to mate with other Stegomyia species, such as Aedes polynesiensis and Ae. aegypti, is well established [42-45]. Moreover, refractoriness in females to conspecific insemination in mosquito species after mating with Ae.albopictus males has been evidenced, either by cross mating experiments [46] or by interspecific implant of male accessory gland secretions [34,47].

The objective of this study was to determine if mating interference takes place between $\mathrm{Ae}$. albopictus and Ae.cretinus. The potential of mating interference between these Stegomyia species was investigated by reciprocal and homologous mating experiments in cages under laboratory conditions. Since the results indicated asymmetric cross mating in favor of Ae. albopictus males, further experimentation was conducted in the lab in order to evaluate whether cross mating proficiency of Ae. albopictus males affects fertility of Ae. cretinus.

\section{Materials and Methods}

\section{Mosquito rearing}

Laboratory strains of Ae. albopictus and Ae.cretinus were established from eggs collected in June 2011, using ovitraps from areas of Rizoupoli ( $\left.38^{\circ} 01^{\prime} 33^{\prime \prime} \mathrm{N}, 23^{\circ} 44^{\prime} 28^{\prime \prime} \mathrm{E}\right)$ and Chalandri ( $38^{\circ}$ $\left.01^{\prime} 29^{\prime \prime} \mathrm{N}, 23^{\circ} 48^{\prime} 18^{\prime \prime} \mathrm{E}\right)$, respectively, located in the greater urban Athens area, Greece. Species discrimination was based on two easily distinguished differences on the scaling pattern of the scutum of female mosquitoes, according to identification key by Darsie and SamanidouVoyadjoglou [21]. On Ae. cretinus' scutum, submedian narrow lines of pale scales exist extending from just posterior to scutal angle to scutellum, and there are lateral lines of pale scales from anterior promotory to wing root. Instead, Ae. albopictus' scutum has neither submedian nor lateral lines of pale scales. Colonies of both species were maintained in the laboratory at 26 $\pm 2^{\circ} \mathrm{C}, 80 \%$ relative humidity, and photoperiod of 16 :8-h (light:dark), in separate rooms of Benaki Phytopathological Institute, Kifissia, Greece. Adult mosquitoes were kept in wooden framed cage $(33 \times 33 \times 33 \mathrm{~cm})$ with a $32 \times 32$ mesh, with easy access to $10 \%$ sucrose solution on a cotton wick. Females were blood fed from senior author's (AG) forearm. Larvae were reared in tap water-filled cylindrical enamel pans with diameter of 35 and $10 \mathrm{~cm}$ deep covered by fine muslin. Approximately 400 larvae were fed ad libitum with powdered fish food (JBL Novo Tom 10\% Artemia) in each pan until the adults emerged. Adult mosquitoes were collected using mouth aspirator and transferred to the rearing cage. Plastic beakers with $100 \mathrm{ml}$ water and strips of moistened filter paper were provided in the cage for oviposition. The eggs were kept wet for a few days and then placed in the pans for hatching.

\section{Cross mating studies}

Cross matings were conducted in a laboratory room $\left(26 \pm 2^{\circ} \mathrm{C}, 80 \%\right.$ relative humidity, and photoperiod of 16:8-h), using virgin males and females of each species, 2-3 days old, originated from the laboratory colonies. Pupae were kept individually in transparent plastic vials to ensure virginity in newly emerged adults. Adults of each sex and species were placed in wooden framed cage $(33 \times 33 \times 33 \mathrm{~cm})$ with a $32 \times 32$ mesh, with easy access to $10 \%$ sucrose solution on a cotton wick. To prevent accidental mating of encaged females through the screen by escaped males flying loose in the rearing room, cages were provided with a second layer of screen 
(muslin) separated by a space of $5 \mathrm{~mm}$. Two trial series of non-choice and choice crosses between Ae. albopictus and Ae. cretinus adults were implemented.

In non-choice homologous and reciprocal crosses 20 males of one species were caged with 20 females either of the same or the other species. Moreover, 20 females alone were held in cages as egg laying control treatment. Five days after entering mosquitoes in the cages a human blood meal (AG) was employed until all females got blood fed. Plastic beakers with $100 \mathrm{ml}$ water and strips of moistened filter paper were provided in the cage for oviposition. Ten days later the eggs laid were counted and maintained for five more days in moistened conditions to ensure embryogenesis. The eggs were hatched in dechlorinated water with powdered fish food applying two subsequent submerges and the emerged larvae were counted. All females were dissected and their spermathecae were examined for the presence of sperm to determine insemination rate. Spermathecae were placed in a drop of saline on a glass slide, covered with a cover slip, and gentle pressure was applied. The slides were then examined for the presence of sperm using phase-contrast illumination at 100x magnification [48]. For egg laying and egg hatching rate four cages, each containing 20 males and 20 females, were used for each homologous and reciprocal cross and virgin female treatment (20 females only). For insemination rate determination, the aforementioned four cages plus two more, thus six in total, each containing 20 males and 20 females were used as replicates.

In choice crosses males were provided with a choice of mate species. Twenty Ae. albopictus males were placed in a cage with 20 Ae. albopictus and 20 Ae. cretinus females. Similarly, $20 \mathrm{Ae}$. cretinus males were caged with 20 Ae. albopictus and 20 Ae. cretinus females. Adults were held in the cage with access to $10 \%$ sucrose for 15 days prior to dissection and determination of insemination rate. Species identification in females after choice cross was easily performed under stereoscope based on the two differences in the scaling pattern of the scutum [21]. When the contact of caged specimens caused loss of scales, we examined the distinguishing character in fore- and mid- tarsi; the claws are toothed in Ae.cretinus, whereas they are simple in Ae. albopictus [22]. Insemination rate was determined by phase-contrast microscopy, alike non-choice crosses. Each treatment was replicated six times.

\section{Reproductive interference of cross mating}

To investigate reproductive interference of cross mating, 20 virgin males of Ae. albopictus were placed with 20 virgin females of Ae. cretinus with $10 \%$ sucrose in three cages under the same laboratory conditions that were described in cross mating studies. Mosquitoes were left to copulate in the cages for 15 days, and then Ae. cretinus females were transferred individually in 1.3 $\mathrm{cm}^{3}(10 \times 10 \times 13 \mathrm{~cm})$ plastic cages, covered in the top with fine muslin, along with one virgin Ae. cretinus male, $2-3$ days old, and sucrose $10 \%$.

Five days later every pair was provided with a human blood meal (AG) and plastic beakers with $100 \mathrm{ml}$ water and strips of moistened filter paper for oviposition. Aedes cretinus males and females were left to mate and oviposit for four weeks. Then the eggs were counted, hatched in dechlorinated water with powdered fish food following two subsequent submergences, and the emerged larvae were counted. As a control, virgin males and females of Ae. cretinus were treated following the same protocol under the same laboratory conditions, using new males for the subsequent pairs.

\section{Statistical analysis}

In non-choice tests, effects of cross mating treatments, including virgin female controls, on number of eggs laid per cage were determined by one-way analysis of variance followed by a Student-Newman-Keuls post hoc test for comparison of mean number of eggs per cage 
between treatments $(a=0.05)$ [49]. Data concerning the effects of cross mating treatments on insemination rate were analyzed using Generalized Linear Model with Poisson distribution with loglink $(\mathrm{a}=0.05)$ [50].

In choice tests, comparison of insemination rate between Ae. albopictus and Ae. cretinus females in each mating cross was performed using non parametric McNemar test for related samples $(a=0.05)[50]$.

In reproductive interference study, $x^{2}$ test $(a=0.05)$ was performed to compare the percentage of Ae.cretinus fertile females that had previously mated with Ae albopictus males and then paired with conspecific males (treatment) with those mated with conspecific males only (control). Non-parametric Mann-Whitney U tests were carried out for pair-wise comparisons of Ae. cretinus eggs laid and percentage of hatched larvae between treatment and control $(\mathrm{a}=0.05)[49]$.

All analyses were conducted using the statistical package SPSS 14.0 [51].

\section{Ethics statement}

For establishment of laboratory mosquito strains no specific permits were required to collect mosquito eggs using ovitraps from areas in Athens, Greece, because they are public areas and are not privately owned or protected. Mosquito egg collections from the field did not involve endangered or protected species. Blood meals were provided to mosquitoes by the senior author's forearm (AG) for experimental purposes with his full consent following medical treatment by applying appropriate anti-pruritic skin gel. An informal ethical group consisting of the Director of the Institute and two members of the Institutional Scientific Council was established and determined that human blood feeding of mosquitoes did not involve human as research subject, thus was not a subject to review.

\section{Results}

In non-choice cross mating studies the number of eggs laid was significantly affected by the cross mating treatment $(\mathrm{F}=45.541$; d.f. $=5,18 ; P<0.0001)$ (Table 1$)$. The average number of eggs laid were significantly different between homospecific and heterospecific crosses. Crossing of Ae. cretinus females with Ae. albopictus males resulted in significantly higher number of eggs compared with the reciprocal crossing. All eggs produced by heterologous crosses were sterile (Table 1). In non-choice tests insemination rate differed significantly between the treatments (Likelihood $x^{2}=428.012$; d.f. $=3 ; P<0.0001$ ) and was very high (100 and $96 \%$ ) in case of intraspecific crosses. Interestingly, in interspecific crosses a considerable percentage of Ae. cretinus females was inseminated (58\%) compared with the very low insemination rate for Ae. albopictus (1\%) (Fig 1).

In choice tests for Ae.albopictus males, insemination rate was significantly higher for Ae. albopictus females (100\%) compared with that for Ae. cretinus females $(31 \%)\left(x^{2}=64.015 ; P<\right.$ $0.0001)$. Accordingly, in case of encaged Ae. cretinus males with females of both species, percentage of inseminated Ae. cretinus females (100\%) was significantly higher than that of Ae. albopictus females (4\%) $\left(x^{2}=89.011 ; P<0.0001\right)$ (Fig 2).

Table 2 shows that in reproductive interference study, Ae. cretinus females paired individually with conspecific males laid eggs, either with previous crossing with Ae. albopictus (67.6 $\pm 3.7)$ or Ae. cretinus $(77.3 \pm 1.5)$ males and mean numbers of eggs did not differ significantly ( $\mathrm{Z}$ $=-1.512 ; P=0.131)$. However, the percentage of fertile Ae. cretinus females paired with Ae. cretinus males individually, after had been crossed with Ae. albopictus males (17.5\%), was significantly lower $\left(x^{2}=77.225\right.$; d.f. $\left.=1 ; P<0.0001\right)$ compared with fertile Ae. cretinus females that were encaged with conspecifics only $(100 \%)$. Mean number of eggs laid and percentage of 
Table 1. Mean number of eggs ( \pm S.E.M) and mean percentage of hatched larvae ( \pm S.E.M) per cage of intra- and inter- specific non choice crosses of 20 virgin Ae. albopictus and Ae. cretinus males and females.

\begin{tabular}{|c|c|c|c|}
\hline Cross mating & $\begin{array}{l}\text { Replicates } \\
\text { (cages) }\end{array}$ & $\begin{array}{l}\text { Mean number of eggs per cage }( \pm S . \\
\text { E.M)* }\end{array}$ & $\begin{array}{l}\text { Mean percentage }(\%) \text { of hatched larvae per cage } \\
( \pm \text { S.E.M) }\end{array}$ \\
\hline $\begin{array}{l}\text { Ae. albopictus + }+ \text { Ae. } \\
\text { albopictus }\end{array}$ & 4 & $498 \pm 38 a$ & $94 \pm 2$ \\
\hline ofe. cretinus $+q$ Ae. cretinus & 4 & $314 \pm 54 b$ & $87 \pm 4$ \\
\hline $\begin{array}{l}\text { Ae. albopictus }+\uparrow A e . \\
\text { cretinus }\end{array}$ & 4 & $213 \pm 28 c$ & 0 \\
\hline $\begin{array}{l}\text { Ae. cretinus }+q \text { Ae. } \\
\text { albopictus }\end{array}$ & 4 & $36 \pm 11 d$ & 0 \\
\hline o Ae. albopictus & 4 & $11 \pm 8 d$ & 0 \\
\hline q Ae. cretinus & 4 & $2 \pm 2 d$ & 0 \\
\hline
\end{tabular}

*Means in a column followed by different letter are significantly different (SNK test, $P<0.05$ ).

doi:10.1371/journal.pone.0127762.t001

hatched larvae by fertile Ae. cretinus females were not significantly affected by cross mating with Ae. albopictus males $(\mathrm{Z}=-1.240 ; P=0.215$ and $\mathrm{Z}=-1.590 ; P=0.112$, respectively)

\section{Discussion}

In the current work a quite high insemination rate of Ae. cretinus females was recorded after heterospecific non-choice crosses with Ae. albopictus males. The ability of Ae. albopictus males to mate with Ae. cretinus females was confirmed in choice experiments. Interestingly, this cross mating behavior for the two species performed in an asymmetric pattern, since Ae. cretinus males mated in negligible rate with Ae. albopictus females throughout reciprocal crosses either in non-choice or choice treatments. Structural incompatibilities of genitalia, differing responses of males to females' flight sound and both the ability to produce and recognize semiochemicals have been identified as essential parameters in Aedes interspecific mating [31,40,52,53,54] and therefore may account for asymmetry in cross mating between Ae. albopictus and Ae. cretinus. Cross mating proficiency of Ae. albopictus males with other Stegomyia mosquito species has been reported by several authors. Results of cage experiments by Nasci et al [43] and

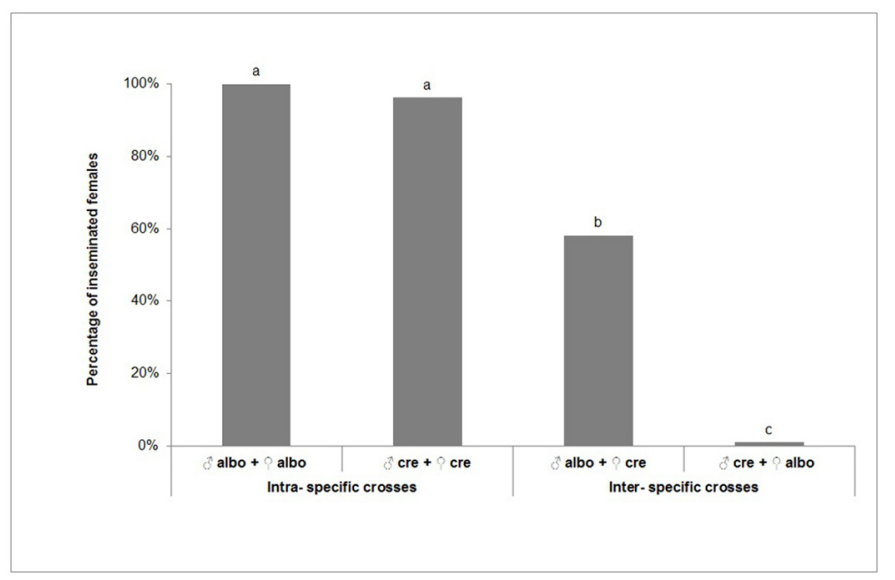

Fig 1. Percentage (\%) of inseminated females after intra- and inter-specific crosses of 20 virgin Ae. albopictus and $\boldsymbol{A e}$. cretinus males and females. ${ }^{*}$ Percentages in a column followed by different letter are significantly different $(P<0.05), 95 \%$ Wald Confidence Interval. * *albo" = Aedes albopictus, "cre" = Aedes cretinus.

doi:10.1371/journal.pone.0127762.g001 


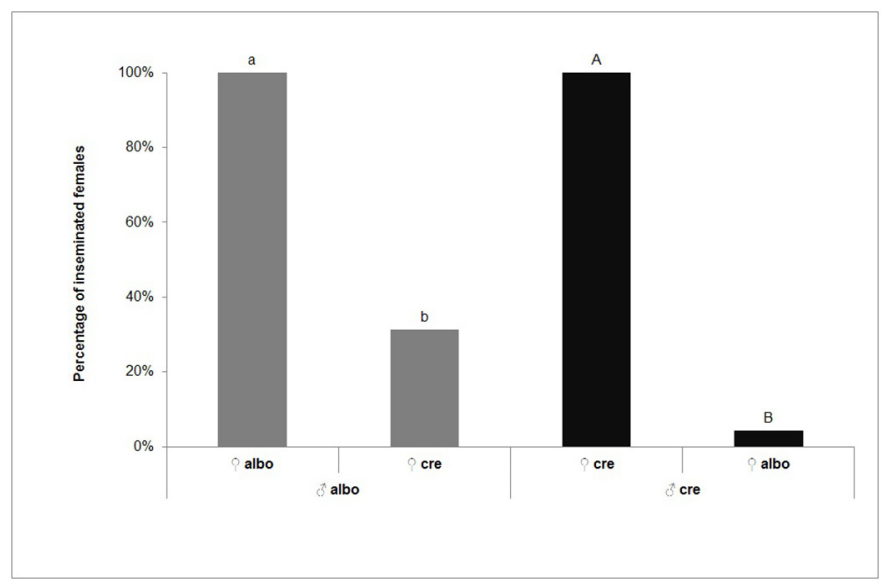

Fig 2. Percentage (\%) of inseminated females after choice crosses of 20 virgin males of Ae. albopictus or Ae. cretinus with 20 Ae. albopictus and 20 Ae. cretinus virgin females. ${ }^{*}$ Percentages in a column followed by different small or capital letter are significantly different $(P<0.05$, McNemar test for related samples). ** "albo" = Aedes albopictus, "cre" = Aedes cretinus.

doi:10.1371/journal.pone.0127762.g002

Bargielowski et al [45] suggested that Ae. aegypti females are more receptive to insemination by Ae. albopictus males than Ae. albopictus females are receptive to insemination by Ae. aegypti males. Nazni et al [44] reported successful bidirectional cross-mating between Ae. albopictus and Ae. aegypti, which was followed by oviposition of sterile eggs. Cross mating between Ae. albopictus males and Ae. polynesiensis females occurred readily under simulated natural conditions in a large cage, where Ae. albopictus males and females of both sexes were engaged, during the course of a long term competition experiment [42].

Interspecific non-choice crosses between Ae. albopictus and Ae. cretinus in both directions produced eggs, but without progeny-hybrid outcome. Infertile cross mating between Aedes members has been observed by Leahy and Craig [40] who worked with multiple laboratory colonies and found that no hybrid offspring was produced in interspecific crosses of Ae. albopictus and Ae. aegypti. Sterile eggs from cross mating were significantly higher in numbers when $A e$. albopictus males crossed with Ae. cretinus females. High ovipositioning by Ae. cretinus in cross mating correlates with the high insemination rate and may be attributed to stimulant substance provided by the male accessory gland. According to Leahy and Craig [55] implants of heterologous male accessory glands to Ae. albopictus and Ae. aegypti females resulted in ovipositioning

Table 2. Oviposition and fertility of Ae. cretinus females previously crossed with Ae. albopictus (treatment) or Ae. cretinus (control) males in groups of 20 and then paired with Ae. cretinus males individually.

\begin{tabular}{|c|c|c|c|c|c|c|}
\hline & \multicolumn{6}{|c|}{ Aedes cretinus females } \\
\hline & \multicolumn{2}{|r|}{ Total } & \multicolumn{4}{|c|}{ Fertile $q$} \\
\hline & $\begin{array}{l}\text { No. } \\
\text { q }\end{array}$ & $\begin{array}{l}\text { Mean No. of eggs per }+( \pm \text { SEM) } \\
* *\end{array}$ & $\begin{array}{l}\text { No. } \\
\text { q }\end{array}$ & $\begin{array}{l}\text { Percentage }(\%) \\
*\end{array}$ & $\begin{array}{l}\text { Mean No. of eggs }( \pm \text { SEM) } \\
* *\end{array}$ & $\begin{array}{l}\text { Mean } \% \text { of hatched larvae }( \pm \text { SEM) } \\
* *\end{array}$ \\
\hline Treatment & 57 & $67.6 \pm 3.7 \mathrm{a}$ & 10 & $17.5 a$ & $69.4 \pm 7.6 a$ & $69.5 \pm 13.6 \mathrm{a}$ \\
\hline control & 54 & $77.3 \pm 1.5 a$ & 54 & $100 b$ & $77.3 \pm 1.5 a$ & $90 \pm 1.7 a$ \\
\hline
\end{tabular}

* Percentages with different letters are significantly different $\left(P<0.05, x^{2}\right.$ test).

** Means in a column followed by the same letter are not significantly different ( $P>0.05$, Mann-Whitney $U$ test).

doi:10.1371/journal.pone.0127762.t002 
of sterile eggs indicating that upon mating a substance stimulus to egg deposition is provided by the male accessory glands.

Aedes females have been observed to copulate several times in their life time [56], and though they are considered as primarily monandrous, examples of multiple insemination (polyandry) exist both in the laboratory and in the field [57-59]. Thus, no adverse effect of the presence of heterospecific males on reproductive success was found in choice laboratory tests for either Ae. albopictus or Ae. aegypti $[60,61]$. The critical question, therefore, is not only whether cross mating occurs, but rather, whether heterospecific mating interferes with conspecific mating and oviposition [61]. The experimental evidence of the current reproductive interference study suggests that the cross inseminated Ae. cretinus females cannot be re-

inseminated by conspecific males and therefore Ae. albopictus males appeared highly effective in sterilizing Ae.cretinus females. Such reproductive interference has been observed under laboratory conditions, where males of Ae. albopictus mated readily with the females of Ae. polynesiensis and these females did not produce viable eggs after engagement with conspecific males [46]. Also, Tripet et al [47] injected heterologous MAG in Ae. aegypti and Ae. albopictus virgin females and reported sterilization for the former species, but no effect on the ability of Ae. albopictus to mate with their own species. In a publication by Craig [34] heterologous implants of MAG from Ae. atropalpus, Ae. triseriatus, Culex pipiens, Ae. scutellaris and Drosophila melanogaster to Ae. aegypti females and from Ae. aegypti and Ae. atropalpus to Ae. triseriatus females significantly affected insemination rate with conspecific males.

Theoretically, if asymmetric mating interference between Ae. albopictus and Ae. cretinus that was evidenced under laboratory conditions, apply in nature it may affect population dynamics of these ecologically homologous species, causing even displacement of Ae. cretinus. Ribeiro [8] suggests that the rate and degree of displacement due to satyrization depends upon the relative density, reproductive and dispersal rates, and on the degree of asymmetry in mating aggressiveness between the two species. The ecological consequences of "reproductive interference", a term for several types of sexual interactions between animal species including heterospecific mating, can be dramatic leading to displacement of one species (sexual exclusion), spatial, temporal, or habitat segregation, changes in life history parameters, and reproductive character displacement [62]. Heterospecific matings and hybridization are often considered to be the types of reproductive interference with the highest fitness losses, as they involve gamete wastage and can lead to sterile offspring or inviable eggs [62]. Our experiments revealed a strong asymmetry in cross mating favoring satyrization of Ae. cretinus by Ae. albopictus and causing detrimental genetic material waste for Ae. cretinus through the production of sterile eggs. Considerably high population densities of Ae. albopictus against low ones of Ae. cretinus, that have been recorded in our field study in Athens [20], provide probably Ae. albopictus with a competitive advantage in the vegetated areas where these species co-exist.

A recent and well-studied example of competitive displacement or reduction between mosquito species was the rapid reduction in range and abundance of Ae. aegypti following the invasion and spread of Ae. albopictus throughout most of the southeastern United States in the 1980 s $[16,17,63-65]$. Laboratory and field data indicate that asymmetric mating interference triggering sterility to Ae. aegypti could constitute a potential explanation for this displacement [41,43-45,47,66]. Interestingly, exposures in cages demonstrated that female Ae. aegypti from populations in Florida sympatric with Ae. albopictus for the past 20 years were significantly less likely than nearby allopatric populations to mate with heterospecific males [45]. Those results indicate rapid sexual selection leading to reproductive character displacement and the potential for satyr-resistant Ae. aegypti to recover from competitive displacements [45]. Aedes albopictus and Ae. cretinus have been detected as sympatric species in vegetated areas of Athens [20], however Ae. cretinus satyr-resistance was not observed in the current study. This might 
happened because mosquito populations that were used to establish laboratory colonies were allopatric and therefore reproductive isolation had not evolved.

Overall, the current laboratory cross mating studies provided evidence for asymmetric mating interference between Ae. albopictus and Ae. cretinus in favor of Ae. albopictus. It is essential to look for possible explanations for this cross mating asymmetry, identifying for example structural compatibilities of genitalia and the role of cues that may be involved in sexual interaction between these species. Further field work is deemed necessary to study if mating interference may account for the limited presence of Ae. cretinus and the extended one of Ae. albopictus in the urban environment of Athens, Greece where these related species co-occur.

\section{Acknowledgments}

We thank Dr Panagiotis Milonas (Benaki Phytopathological Institute) for his suggestions and critical comments on the manuscript.

\section{Author Contributions}

Conceived and designed the experiments: AG NE. Performed the experiments: AG GK. Analyzed the data: AG DPP. Contributed reagents/materials/analysis tools: AM. Wrote the paper: AG DPP GK AM NE.

\section{References}

1. DeBach P (1966) The competitive displacement and coexistence principles. Annu. Rev. Entomol. 11: 183-212.

2. Reitz S, Trumble J (2002) Competitive displacement among insects and arachnids. Annu. Rev. Entomol. 47: 435-465. PMID: 11729081

3. Mack RN, Simberloff D, Lonsdale WM, Evans H, Clout M, Bazzaz F (2000) Biotic invasions: Causes, epidemiology, global consequences, and control. Ecol. Appl. 10: 689-710.

4. Lounibos LP (2007) Competitive displacement and reduction. J. Am. Mosq. Control Assoc. 23 (suppl. 2): 276-282.

5. Ribeiro J, Spielman A (1986) The satyr effect: a model predicting parapatry and species extinction. Amer. Nat. 128: 513-528.

6. Lounibos LP (2002) Invasions by insect vectors of human disease. Annu. Rev. Entomol. 47: 233-266. PMID: 11729075

7. Juliano SA, Lounibos LP (2005) Ecology of invasive mosquitoes: effects on resident species and on human health. Ecol. Lett. 8: 558-574. PMID: 17637849

8. Ribeiro J (1988) Can satyrs control pests and vectors? J. Med. Entomol. 25: 431-440. PMID: 3204622

9. Vanderplank FL (1947) Experiments in the hybridization of tsetse flies (Glossina, Diptera) and the possibility of a new method of control. Trans. R. Entomol. Soc. Lond. 98: 1-18.

10. Sutherst RW (1987) The dynamics of hybrid zones between tick (Acari) species. Int. J. Parasitol. 17: 921-926. PMID: 3583541

11. Spielman A, Feinsod F (1979) Differential distribution of peridomestic Aedes mosquitoes on Grand Bahama Island. Trans. R. Soc. Trop. Med. Hyg. 73: 381-384. PMID: 555063

12. Enserink M (2008) A mosquito goes global. Science 320: 864-866. doi: 10.1126/science.320.5878 864 PMID: 18487167

13. Medlock JM, Hansford KM, Schaffner F, Versteirt V, Hendrickx G, Zeller H et al (2012) A review of the invasive mosquitoes in Europe: Ecology, public health risks, and control options. Vector Borne Zoonotic Dis. 12: 1-13. doi: 10.1089/vbz.2011.0705 PMID: 21995261

14. Gratz NG (2004) Critical review of the vector status of Aedes albopictus. Med. Vet. Entomol. 18: 215227. PMID: 15347388

15. Bonizzoni M, Gasperi G, Chen X, James AA (2013) The invasive mosquito species Aedes albopictus: current knowledge and future perspectives. Trends Parasitol. 29: 460-468. doi: 10.1016/j.pt.2013.07. 003 PMID: 23916878

16. Hawley WA (1988) The biology of Aedes albopictus. J. Am. Mosq. Control Assoc. 4 (suppl. 1): 1-40. 
17. Estrada-Franco JG, Craig GB (1995) Biology, disease relationships, and control of Aedes albopictus, pp. 1-49. Pan American Health Organization, Pan American Sanitary Bureau, Regional Office of the World Health Organization. Technical paper no. 42.

18. Samanidou-Voyadjoglou A, Patsoula E, Spanakos G, Vakalis NC (2005) Confirmation of Aedes albopictus (Skuse) (Diptera: Culicidae) in Greece. Eur. Mosq. Bull. 19: 10-11.

19. Giatropoulos A, Michaelakis A, Koliopoulos G, Pontikakos CM (2012) Records of Aedes albopictus and Aedes cretinus (Diptera: Culicidae) in Greece from 2009 to 2011. Hell. Plant Prot. J. 5: 49-56.

20. Giatropoulos A, Emmanouel N, Koliopoulos G, Michaelakis A (2012) A study on distribution and seasonal abundance of Aedes albopictus (Diptera: Culicidae) population in Athens, Greece. J. Med. Entomol. 49: 262-269. PMID: 22493842

21. Darsie RF, Samanidou-Voyadjoglou A (1997) Keys for the indentification of the mosquitoes of Greece. J. Am. Mosq. Control Assoc. 13: 247-254. PMID: 9383766

22. Darsie RF (1999) Description of the pupa of Aedes cretinus Edwards. A key to the pupae of the albopictus subgroup, subgenus Stegomyia Theobald, genus Aedes meigen and characters to separate the European Stegomyia species (Diptera Culicidae). Proceedings of the Entomological Society of Washington, 10: 614-618.

23. Reinert JF, Harbach RE, Kitching IJ (2004) Phylogeny and classification of Aedini (Diptera: Culicidae), based on morphological characters of all life stages. Zool. J. Linnean Soc. 142: 289-368.

24. Savage HM (2005) Classification of mosquitoes in tribe Aedini (Diptera: Culicidae): Paraphylyphobia, and classification versus cladistic analysis. J. Med. Entomol. 42: 923-927. PMID: 16465729

25. Polaszek A (2006) Two words colliding: resistance to changes in the scientific names of animalsAedes vs Stegomyia. Trends Parasitol. 22: 8-9. PMID: 16300998

26. Becker N, Petric D, Zgomba M, Boase C, Madon M, Dahl C et al (2010) Mosquitoes and Their Control. Springer-Verlag Berlin Heidelberg. Second edition, 577 p.

27. Samanidou-Voyadjoglou A, Koliopoulos G (1998) Some notes on Aedes (Stegomyia) cretinus Edwards (Culicidae) in northern Athens, Attiki, Greece, pp.194-195. In: Fourth International Congress of Dipterology, 6-13 September, Oxford, United Kingdom.

28. Alten B, Bellini R, Caglar SS, Simsek FM, Kaynas S (2000) Species composition and seasonal dynamics of mosquitoes in the Belek region of Turkey. J. Vector Ecol. 25: 146-154. PMID: 11217213

29. Caglar SS, Alten B, Bellini R, Simsek FM, Kaynas S (2003) Comparison of nocturnal activities of mosquitoes (Diptera: Culicidae) sampled by New Jersey light traps and $\mathrm{CO}^{2}$ traps in Belek, Turkey. J. Vector Ecol. 28: 1-11. PMID: 12831123

30. Clements AN (1999) Biology of Mosquitoes: Sensory Reception and Behavior ( Volume II). CABI Publishing ( New York City) 1999, 740 p.

31. Oliva CF, Damiens D, Benedict MQ (2013) Male reproductive biology of Aedes mosquitoes. Acta Trop. doi: 10.1016/j.actatropica.2013.11.021

32. Spielman A, Leahy MG, Skaff V (1967) Seminal loss in repeatedly mated female Aedes aegypti. Biol. Bull. 132: 404-412.

33. Spielman A, Leahy MG, Skaff V (1969) Failure of effective insemination of young female Aedes aegypti mosquitoes. J. Insect Physiol. 15: 1471-1479. PMID: 5348111

34. Craig GB (1967) Mosquitoes: Female monogamy induced by male accessory gland substance. Science 157: 1499-1501.

35. Fuchs MS, Craig GB, Hiss EA (1968) The biochemical basis of female monogamy in mosquitoes. I. Extraction of the active principle from Aedes aegypti. Life Science 7: 835-839. PMID: 5672305

36. Gwadz RW (1972) Neuro-hormonal regulation of sexual receptivity in female Aedes aegypti. J. Insect Physiol. 18: 259-266. PMID: 5016034

37. Shutt B, Stables L, Aboagye-Antwi F, Moran J, Tripet F (2010) Male accessory gland proteins induce female monogamy in anopheline mosquitoes. Med. Vet. Entomol. 24: 91-94. doi: 10.1111/j.1365-2915. 2009.00849.x PMID: 20377737

38. Helinski MEH, Deewatthanawong P, Sirot LK, Wolfner MF, Harrington LC (2012) Duration and dosedependency of female sexual receptivity responses to seminal fluid proteins in Aedes albopictus and Ae. aegypti mosquitoes. J. Insect Physiol. 58: 1307-1313. doi: 10.1016/j.jinsphys.2012.07.003 PMID: 22796224

39. Oliva CF, Damiens D, Vreysen MJB, Lemperiere G, Gilles J (2013) Reproductive strategies of Aedes albopictus (Diptera: Culicidae) and implications for the sterile insect technique. PLoS ONE, 8: e78884. doi: 10.1371/journal.pone.0078884 PMID: 24236062

40. Leahy MG, Craig GB Jr (1967) Barriers to hybridization between Aedes aegypti and Aedes albopictus (Diptera Culicidae). Evolution 21: 41-58. 
41. Lima-Camara TN, Codeo CT, Honorio NA, Bruno RV, Peixot AA, Lounibos LP (2013) Male accessory gland substances from Aedes albopictus affect the locomotor activity of Aedes aegypi females. Mem. Inst. Oswaldo Cruz 108 (Suppl. I): 18-25. doi: 10.1590/0074-0276130457 PMID: 24473810

42. Ali SR, Rozeboom LE (1971) Cross-mating between Aedes (s.) polynesiensis marks and Aedes (s.) albopictus skuse in a large cage. Mosq. News 31: 80-84.

43. Nasci RS, Hare SG, Willis FS (1989) Interspecific mating between Louisiana strains of Aedes albopictus and Aedes aegypti in the field and laboratory. J. Am. Mosq. Control Assoc. 5: 416-421. PMID: 2584975

44. Nazni W, Lee H, Dayang H, Azahari A (2009) Cross-mating between malaysian strains of Aedes aegypti and Aedes albopictus in the laboratory. Southeast Asian J. Trop. Med. Public Health 40: 41-46.

45. Bargielowski I E, Lounibos LP, Carrasquilla MC (2013) Evolution of resistance to satyrization through reproductive character displacement in populations of invasive dengue vectors. PNAS 110: 28882892. doi: 10.1073/pnas.1219599110 PMID: 23359710

46. Gubler DJ (1970) Induced sterility in Aedes (stegomyia) polynesiensis marks by cross-insemination with Aedes (Stegomyia) albopictus Skuse. J. Med. Entomol. 7: 65-70. PMID: 5435810

47. Tripet F, Lounibos LP, Robbins D, Moran J, Nishimura N, Blosser EM (2011) Competitive reduction by satyrization? Evidence for interspecific mating in nature and asymmetric reproductive competition between invasive mosquito vectors. Am. J. Trop. Med. Hyg. 85: 265-270. doi: 10.4269/ajtmh.2011.100677 PMID: 21813845

48. Benedict $M Q$ (2007) Dissecting spermathecae to determine insemination status. In: Methods in Anopheles Research. Center for Disease Control (CDC). Atlanda, USA.

49. Sokal RR, Rohlf FJ (1995) Biometry, 3rd ed. W. H. Freeman, New York.

50. Agresti A (2013) Categorical Data Analysis, 3rd Edition. Published by Wiley and Sons, Inc, Hoboken, New Jersey, $744 \mathrm{p}$.

51. SPSS (2004) SPSS 14 for Windows users guide. SPSS Inc., Chicago, IL.

52. Nijhout HF, Craig GB (1971) Reproductive isolation in Stegomyia mosquitoes. III Evidence for a sexual pheromone. Entomol. Exp. Appl. 14: 399-412.

53. Durkopf RE, Hartberg WK (1992) Differences in male mating response and female flight sounds in Aedes aegypti and Ae. albopictus (Diptera: Culicidae). J. Med. Entomol. 29: 796-801. PMID: 1404257

54. Cabrera M, Jaffe K (2007) An aggregation pheromone modulates lekking behaviorin the vector mosquito Aedes aegypti (Diptera: Culicidae). J. Am. Mosq. Control Assoc. 23: 1-10. PMID: 17536361

55. Leahy MG, Craig GB (1965) Accessory gland substance as a stimulant for oviposition in Aedes aegypti and $A$. albopictus. Mosq. News 25: 448-452.

56. Roth LM (1948) A study of mosquito behavior: an experimental laboratory study of the sexual behavior of Aedes aegypti (Linnaeus). Am. Midl. Nat. 40: 265-352.

57. Gwadz RW, Craig GB (1970) Female polygamy due to inadequate semen transfer in Aedes aegypti. Mosq. News 30: 355-60.

58. Boyer S, Toty C, Jacquet M, Lemperiere G, Fontenille D (2012) Evidence of multiple inseminations in the field in Aedes albopictus. PLoS ONE 7: e42040. doi: 10.1371/journal.pone.0042040 PMID: 22916116

59. Helinski MEH, Valerio L, Facchinelli L, Scott TW, Ramsey J, Harrington LC (2012) Evidence of polyandry for Aedes aegypti in semifield enclosures. Am. J. Trop. Med. Hyg. 86: 635-641. doi: 10.4269/ ajtmh.2012.11-0225 PMID: 22492148

60. Black WC, Rai KS, Turco BJ, Arroyo DC (1989) Laboratory study of competition between United States strains of Aedes albopictus and Aedes aegypti (Diptera: Culicidae). J. Med. Entomol. 26: 260-271. PMID: 2769704

61. Harper JP, Paulson SL (1994) Reproductive isolation between Florida strains of Aedes aegypti and Aedes albopictus. J. Am. Mosq. Control Assoc. 10: 88-92. PMID: 8014633

62. Groning J, Hochkirch A (2008) Reproductive interference between animal species. Q. Rev. Biol. 83: 257-282. PMID: 18792662

63. Hawley WA, Reiter P, Copeland RS, Pumpuni CB, Craig JGB (1987) Aedes albopictus in North America: Probable introduction in used tires from northern Asia. Science 236: 1114-1116. PMID: 3576225

64. Hobbs I, Hugos E, Eichold B (1991) Replacement of Ae. aegypti by Ae. albopictus in Mobile, Alabama. J. Am. Mosq. Control Assoc. 7: 488-489. PMID: 1791461

65. O'Meara GF, Evans LF, Gettman AD, Cuda JP (1995) Spread of Aedes albopictus and decline of Ae. aegypti (Diptera: Culicidae) in Florida. J. Med. Entomol. 32: 554-562. PMID: 7650719

66. Lounibos LP, Suárez S, Menéndez Z, Nishimura N, Escher RL, O'Connell SM et al (2002) Does temperature affect the outcome of larval competition between Aedes aegypti and Aedes albopictus? J. Vector Ecol. 27: 86-95. PMID: 12125878 